\title{
O PROEJA NO IFRN-CAMPUS MOSSORÓ POR SEUS ESTUDANTES
}

\author{
J. M. N. SILVA e A. L.T. F. SÁ \\ Instituto Federal de Educação, Ciência e Tecnologia do Rio Grande do Norte \\ Instituto Federal de Educação, Ciência e Tecnologia do Rio Grande do Norte \\ moises.silva@ifrn.edu.br; lanuzia.sa@ifrn.edu.br
}

Artigo submetido em junho/2016 e aceito em setembro/2016

DOI: $10.15628 /$ holos.2016.4711

\section{RESUMO}

$\mathrm{O}$ artigo discute a temática educação de jovens e adultos (EJA). O objetivo é analisar, sob a perspectiva dos estudantes, como o campus Mossoró do IFRN vem materializando a proposta curricular do curso técnico integrado em Edificações na modalidade EJA, oferecido no âmbito do Programa Nacional de Integração da Educação Profissional com a Educação Básica na Modalidade de Educação de Jovens e Adultos (PROEJA). Metodologicamente, o estudo se insere na categoria exploratório-descritiva, com base na dialética. As fontes de informação são o Projeto Pedagógico do Curso e os dados (questionários e entrevistas) coletados dos estudantes do último semestre da primeira turma do curso. Considerando as práticas pedagógicas desenvolvidas pelos professores, constata-se que não há a materialização concreta do currículo integrado no curso e, sim, que apenas algumas ações didáticas, muito específicas e não sistematizadas nem planejadas coletivamente, concorrem para esse fim.

PALAVRAS-CHAVE: PROEJA, Práticas Pedagógicas, Currículo Integrado.

\section{CONCEPTIONS OF TECHNICAL TRAINING OF MIDDLE LEVEL ADOPTED BY IFRN: SPECIFICITIES AND (DIS) CONTINUITIES}

\section{RESUMEN}

The article discusses the issue of education youth and adults (EJA). The objective is to analyze, from the perspective of students, as Mossoro campus IFRN comes materializing the proposed curriculum of integrated technical course in Building the EJA modality, offered under the National Programme Vocational Education Integration with Basic Education in the Modality Youth and Adult education (PROEJA). Methodologically, the study is included in the exploratory-descriptive category, based on dialectics. The sources of information are the Pedagogical Project of the Course and the data (questionnaires and interviews) collected from students last semester of the first class of the course. Considering the pedagogical practices developed by teachers, it appears that there is no concrete evidence of an integrated curriculum in the course and, yes, that only a few didactic actions, very specific and not systematic or planned collectively contribute to this end.

KEYWORDS: PROEJA, Pedagogical Practices, Integrated Curriculum. 


\section{INTRODUÇÃO}

No segundo semestre de 2006, o campus Mossoró, do Instituto Federal de Educação, Ciência e Tecnologia do Rio Grande do Norte (IFRN), iniciou a oferta do curso técnico de nível médio integrado em Edificações na modalidade Educação de Jovens e Adultos (EJA), no âmbito do Programa Nacional de Integração da Educação Profissional com a Educação Básica na Modalidade de Educação de Jovens e Adultos (PROEJA).

O mencionado curso fundamenta-se no princípio da politecnia e da indissociabilidade entre trabalho, ciência, tecnologia e cultura, visando à formação humana integral de jovens e adultos, isto é, além de qualificar esses sujeitos para a execução e o gerenciamento de obras de edificações, o curso objetiva, também, possibilitar o domínio de diferentes linguagens, a compreensão dos conteúdos científico-tecnológicos e o diálogo dos valores culturais, éticos e estéticos e as mudanças societárias, conferindo um maior sentido ao exercício profissional, à cidadania e ao prosseguimento dos estudos.

Assim sendo, objetiva-se neste trabalho analisar como vem se materializando a proposta curricular do mencionado curso, sob a perspectiva dos estudantes.

Metodologicamente, o estudo se insere na categoria exploratório-descritiva, tendo como fio condutor a contradição (SILVA; MENEZES, 2001). As fontes de informação são o Projeto Pedagógico do Curso e os dados (questionário e entrevistas) colhidos dos estudantes do último semestre da primeira turma do curso mencionado, por meio da pesquisa Investigando a implementação do ensino médio integrado aos cursos técnicos de nível médio no CEFET-RN a partir de 2005: o currículo e a gestão, desenvolvida, entre 2009 e 2010, pelo Núcleo de Pesquisa em Educação, do IFRN.

A relevância do trabalho decorre da necessidade de compreender como o campus Mossoró do IFRN vem concretizando a proposta do PROEJA, delineada pelo Governo Lula da Silva, no tocante à formação profissional e à ampliação da cidadania dos jovens e adultos trabalhadores.

O trabalho está organizado em três partes. Na primeira caracteriza-se o PROEJA; na segunda aborda-se o perfil do curso de Edificações na modalidade EJA; e na terceira, analisa-se a materialização do curso, a partir da percepção dos estudantes.

\section{O PROEJA}

O Programa Nacional de Integração da Educação Profissional com a Educação Básica na Modalidade de Educação de Jovens e Adultos (PROEJA), foi instituído, em 2005, pelo governo Lula da Silva, por meio do Decreto n. 5.478, de 24 de junho, no âmbito das Instituições Federais de Educação Tecnológica, com duas formas de oferta, ambas restrita ao ensino médio: cursos de formação inicial e continuada de trabalhadores e cursos de educação profissional técnica de ensino médio. (BRASIL, 2005).

Em 2006, esse mesmo Governo, mediante o Decreto n. 5.840, de 13 de julho, ampliou o raio de ação do PROEJA para a educação básica, o âmbito das instituições ofertantes, incluindo as instituições públicas dos sistemas de ensino estaduais e municipais e as entidades privadas 
nacionais de serviço social, aprendizagem e formação profissional vinculada ao sistema sindical e a denominação do Programa, conforme prescrita no parágrafo anterior. (BRASIL, 2006).

Não é demais observar que até a aprovação da Lei n. 9.394, de 20.12.1996 - Lei de Diretrizes e Bases da Educação Nacional (LDB/1996) - a EJA era concebida, pelo Estado brasileiro, como sinônimo de alfabetização de adultos, sempre atrelada a projetos assistencialistas e compensatórios, muitas vezes desenvolvidos em ambientes não escolares: na família, na igreja, nas associações, nos locais de trabalho etc., sem qualquer articulação com a educação básica e com a educação profissional.

Mesmo com a oferta pública de alfabetização para jovens, adultos e idosos, por meio do Programa Brasil Alfabetizado, instituído pelo Governo Lula da Silva, em 2003, a EJA continua circunstanciada: majoritariamente, os cursos são ofertados no turno noturno, com a utilização de material didático inadequado (o mesmo utilizado para os adolescentes), currículos que não atendem às expectativas dos estudantes e professores sem formação específica para atuar com esse público.

O PROEJA coloca-se como uma alternativa inovadora para romper com a descontinuidade dos estudos de jovens e adultos, já que objetiva, no caso da oferta de cursos de formação inicial e continuada de trabalhadores, associar a educação profissional ao ensino fundamental ou ao ensino médio, objetivando a elevação do nível de escolaridade; e, no de cursos de educação profissional técnica de nível médio, articular a educação profissional ao ensino médio, com o fim da formação orientada ao exercício de profissões técnicas. (BRASIL, 2006; MACHADO, 2006).

Dessa forma, o PROEJA visa a atender demanda de jovens e adultos excluída do sistema educacional, e que constitui uma parcela significativa da população brasileira economicamente ativa, oferecendo formação e qualificação profissional e formação cidadã, além de possibilitar a ampliação da escolaridade e a continuidade de estudos.

O princípio norteador do PROEJA é a formação humana integral, ou seja, "[...] uma formação que permita a mudança de perspectiva de vida por parte do aluno; a compreensão das relações que se estabelecem no mundo do qual ele faz parte; a ampliação de sua leitura de mundo e a participação efetiva nos processos sociais." (BRASIL, 2007, p. 7).

A formação integral representa uma ruptura com a formação unilateral decorrente da divisão do trabalho na sociedade capitalista, pois diz respeito ao desenvolvimento de todas as faculdades do ser humano - intelectual, laboral, social, ética, estética etc. - a fim de que possa compreender as relações que se estabelecem nas atividades socioculturais e no mundo do trabalho, ampliar sua leitura de mundo e exercer de forma autônoma e ativa sua cidadania em todos os processos sociais.

A perspectiva dessa formação se coaduna, portanto, com o pensamento freireano de autonomia, do sujeito que não apenas constata o que ocorre para se adaptar, mas avalia e intervém para transformar a realidade, "[...] mesmo sabendo que as condições materiais, econômicas, sociais e políticas, culturais e ideológicas em que nos achamos geram quase sempre barreiras de difícil superação [...]". (FREIRE, 1996, p. 54).

Assim, o PROEJA, integrando a educação profissional aos ensinos fundamental e médio, etapas da educação básica, pretende possibilitar aos jovens e adultos a apropriação de saberes científico-tecnológicos complementados por uma formação cidadã, para qualificada (re)inserção 
no mundo do trabalho, a ampliação de escolarização e melhor integração socioeconômica, política e cultura.

Isto implica, por um lado, estruturar os cursos, preferencialmente, em sintonia com as demandas local e regional, de forma a contribuir com o fortalecimento das estratégias de desenvolvimento socioeconômico e cultural e, por outro, considerar as características dos jovens e adultos atendidos, um corpo teórico-metodológico com identidade própria e diferente daquele destinado aos adolescentes egressos do ensino fundamental, a formação de professores para atuar no Programa, a organização curricular integrada e a utilização de material didático e metodologias que favoreçam a aprendizagem desses sujeitos.

\section{O CURSO TÉCNICO INTEGRADO DE EDIFICAÇÕES NA MODALIDADE EJA NO CAMPUS MOSSORÓ}

O campus Mossoró do IFRN, observando a demanda da região Oeste Potiguar por profissionais na área de construção civil e em atendimento à determinação contida no Decreto $\mathrm{n}$. $5.840 / 2006$, iniciou a oferta do curso técnico integrado em Edificações na modalidade EJA, no segundo semestre de 2006.

A primeira turma desse curso, ofertada para funcionamento no turno noturno, foi constituída por 42 estudantes, a maioria dos quais, além de estar inserida no mercado de trabalho, alegou que o retorno aos estudos se deu devido à qualidade do ensino que o Campus oferece, a possibilidade de uma habilitação profissional, melhores oportunidades de emprego e continuar os estudos em nível superior. A fala do estudante 2 é bem representativa:

Para mim estar aqui é uma grande alegria apesar de trabalhar o dia todo e ter a idade que já tenho. Eu tive vontade de fazer esse Curso porque trabalho na área da construção civil. Eu tinha que conhecer a coisa melhor, pois eu trabalho há muito tempo e não sabia o que era a construção civil. Hoje eu sei o que é e quero aprender mais. Quero ser um melhor profissional. (ESTUDANTE 2).

De acordo com o Plano de Curso, o curso de Edificações está organizado em regime seriado semestral, constituído de oito semestres, estruturado em uma matriz curricular composta por três partes: a) núcleo comum, com 1.530 horas, integrando disciplinas das três áreas de conhecimentos do ensino médio, b) parte diversificada, com 240 horas e disciplinas voltadas à compreensão das relações existentes no mundo do trabalho e sua articulação com os conhecimentos acadêmicos e c) formação profissional, como 1.050 horas e disciplinas específicas do curso; além de 400 horas destinadas à prática profissional, perfazendo uma carga horária total de 3.220 horas. (CENTRO FEDERAL DE EDUCAÇÃO TECNOLÓGICA DO RIO GRANDE DO NORTE, 2006).

O perfil profissional, de acordo com o referido Plano de Curso, é formar profissionaiscidadãos para desenvolver e executar projetos de construções prediais e/ou de manutenção e restauração de obras; elaborar orçamento de obras; assistir no estudo e desenvolvimento de projetos e pesquisas tecnológicas na área de edificações; e instalar e gerenciar serviços de manutenção de equipamentos e de instalações em edificações.

Ainda segundo o Plano de Curso, o curso de Edificações está fundamentado no princípio da politecnia, tendo o trabalho como princípio educativo, a ciência, a tecnologia e a cultura como 
eixos estruturantes do currículo, de modo que cada semestre é constituído por um conjunto de disciplinas baseadas na relação teoria-prática, conduzindo a um fazer pedagógico contextualizado e interdisciplinar, subsidiado por atividades como seminários, visitas técnicas, práticas laboratoriais e desenvolvimento de projetos, entre outras.

A pertinência das disciplinas em cada semestre, abalizadas na indissociabilidade das dimensões referidas, coloca-as numa perspectiva relacional, sem descaracterizar a importância de cada uma delas e, por conseguinte, facilita a materialização do currículo integrado e o alcance da formação humana integral.

Até porque o sentido de um currículo integrado é bem mais amplo do que o mero reunir, em um mesmo currículo, processos educativos com finalidades próprias (ensino médio e educação profissional). Implica considerar uma formação em que os dois tipos de conhecimentos (formação geral e formação profissional) estejam imbricados desde o início do curso, de modo que os aspectos científico-tecnológicos, humanísticos e culturais estejam integrados e contemplados de forma equânime.

Não sem razão Ramos (2005, p. 122) afirma: “[...] a integração exige que a relação entre conhecimentos gerais e específicos seja construída continuamente ao longo da formação, sob os eixos do trabalho, da ciência, da tecnologia e da cultura."

Por isso, a materialização do currículo integrado no curso de Edificações exige práticas pedagógicas pensadas coletivamente, de modo a proporcionar ao estudante a compreensão dos fundamentos científicos e tecnológicos que permeiam a área de construção civil e as relações econômicas, políticas, sociais e culturais presentes nas sociedades.

Afinal, como afirma Machado (2010, p. 81), “[...] se a realidade existente é uma totalidade integrada não pode deixar de sê-lo o sistema de conhecimentos produzidos pelo homem a partir dela, para nela atuar e transformá-la. Tal visão de totalidade também se expressa na práxis do ensinar e aprender."

Assim, é imperioso investigar se as práticas pedagógicas desenvolvidas pelos professores no campus Mossoró convergem para a materialização do currículo integrado, já que a fragmentação dos saberes (teoria versus prática; geral versus específico) presente no currículo que o próprio campus desenvolvia, dificulta a compreensão ampla da realidade e uma formação integral dos estudantes.

\section{PRÁTICAS PEDAGÓGICAS ORIENTADAS À INTEGRAÇÃO CURRICULAR}

O currículo integrado, ainda que organizado em um conjunto de disciplinas onde se aprofundam conceitos específicos, exige interação, planejamento coletivo e reflexão conjunta dos docentes ao longo de todo o curso, a fim de estabelecer práticas pedagógicas interdisciplinares ${ }^{1}$ que concorram para uma sólida formação científico-tecnológica-cultural dos estudantes.

\footnotetext{
${ }^{1}$ Por prática pedagógica entendem-se as ações didáticas que acontecem na escola desde as práticas de organização discursiva até a ação do processo ensino-aprendizagem, como por exemplo, planejamento, reuniões pedagógicas, conselho de classe, aulas, eventos científico-culturais, visitas técnicas etc. E por interdisciplinaridade, na dimensão metodológica, a interação recíproca, o diálogo permanente, entre duas ou mais disciplinas ou campos de conhecimento, de modo a romper as estruturas fragmentadas de cada uma delas e alcançar a unidade do saber; na
} 
Assim, o trabalho interdisciplinar se apresenta como uma necessidade imperativa à materialização do currículo integrado, não a única, uma vez que essa atividade didática dar sentido ao imbricamento das categorias trabalho, ciência, tecnologia e cultura, bem como estimula, nos estudantes, a sociabilidade e o pensamento crítico e, por isso, a interação entre as diversas disciplinas deve ser desenvolvida sistematicamente, não havendo redução ou eliminação da autonomia de cada uma delas.

Nesse sentido, o que se espera é que os professores do ensino médio busquem relações entre a sua disciplina e o sentido dela para a formação do profissional-cidadão em cada curso técnico que estiver atuando e, assim, superar o ensino livresco presente nesta etapa educacional. Já para os docentes de formação profissional que relacionem os conhecimentos científicotecnológicos que estão na base de suas disciplinas aos aspectos sociais e históricos de produção e utilização dos mesmos, rompendo com o viés excessivamente técnico-operacional. (MACHADO, 2010).

No caso específico do PROEJA no IFRN-campus Mossoró, o questionário aplicado aos estudantes sugere algumas práticas pedagógicas que, hipoteticamente, contribuíram, durante o curso, para a materialização do currículo integrado: a elaboração de trabalhos para apresentação em eventos científico-tecnológicos ou artístico-culturais; a participação em atividades que integram professores e conteúdo de duas ou mais disciplinas; a participação em projetos comunitários; a realização de aulas de campo; e a realização da prática profissional.

Na percepção de $67 \%$ dos 18 estudantes $^{2}$ que responderam ao questionário, a elaboração de trabalhos para apresentação em eventos científico-tecnológicos ou artístico-culturais na Instituição contribuíram, no desenvolvimento do curso, para a integração entre as disciplinas do ensino médio e as da educação profissional.

Vale ressaltar que, anualmente, o campus Mossoró realiza a Exposição Científica, Tecnológica e Cultural (EXPOTEC), evento em que os discentes, orientados por professores de uma ou mais disciplinas, desenvolvem experimentos, protótipos e jogos didáticos, como também realizam exposições, oficinas, comunicações e minicursos sobre assuntos na sua área de atuação, e apresentam à sociedade.

Esse evento é, de fato, potencialmente importante para a prática interdisciplinar, pois pode envolver distintas disciplinas e áreas do conhecimento no desenvolvimento das atividades. Todavia, a participação é voluntária, não envolvendo todos os estudantes, nem todos os professores, e a elaboração dos trabalhos geralmente começa a ser feita nas semanas que antecedem a EXPOTEC, o que caracteriza uma prática de caráter pontual, apenas.

Quanto à participação em atividades que integram professores e conteúdo de duas ou mais disciplinas, $61 \%$ dos estudantes apontaram que contribuíram para a integração. Na entrevista coletiva um estudante relatou: " a professora de Língua Portuguesa que nos acompanhou até o 60 período, preocupou-se em trabalhar os conteúdos, relacionando-os à área da Construção Civil. Ela nos ensinou a fazer relatórios e cartas comerciais." Um outro declarou: "Em química, o professor deu a matéria de forma normal, mas não associou. Língua portuguesa, física, matemática,

dimensão ético-política, funda-se na dialética da realidade social, isto é, decorre da compreensão dos elementos históricos, culturais e políticos presentes na sociedade, em seu caráter contraditório, a fim de reconhecer o ser social enquanto totalidade histórica. (FRIGOTTO, 2008; KRÜGER, 2010).

${ }^{2}$ A primeira turma do curso PROEJA-Edificações apresentou 19 estudantes concluintes. 
geografia, sempre os professores estavam voltados a relacionar os conteúdos a nossa área." E um terceiro foi enfático: "as disciplinas do ensino médio foram dadas antes e as técnicas depois. Agora [no final do curso] não tem mais nada de ensino médio. Se tivessem dado junto, seria mais fácil para nós associarmos os conteúdos de umas disciplinas com as outras."

Pelas falas dos estudantes pode-se deduzir que as práticas interdisciplinares acontecem esporadicamente e de forma assistemática, sem qualquer planejamento prévio e sem envolver o coletivo dos docentes que atuam em cada turma; o que há é o esforço de alguns professores em estabelecer uma relação entre o conteúdo que ministra e a perspectiva do curso em que atuam.

Ademais, a afirmação do último estudante corrobora que a segmentação do currículo do curso de Edificações - primeiro as disciplinas de ensino médio, depois as de formação profissional -, não favorece a integração curricular. A esse respeito, concordamos como Machado quando afirma:

Se a realidade existente é uma totalidade integrada não pode deixar de sê-lo o sistema de conhecimentos produzidos pelo homem a partir dela, para nela atuar e transformá-la. Tal visão de totalidade também se expressa na práxis do ensinar e aprender. Por razões didáticas, se divide e se separa o que está unido. Por razões didáticas, também se pode buscar a recomposição do todo. (MACHADO, 2010, p.81).

O currículo integrado vai mais além! Ele requer práticas compartilhadas e de equipe ao longo de todo o curso, tendo o diálogo como elemento fundante para a participação e a capacidade de trabalhar coletivamente, bem como para (re)construir o conhecimento continuamente em conjunto.

Já para apenas $33 \%$ dos estudantes a participação em projetos comunitários cujas atividades mobilizam conhecimentos relacionados com o curso contribuíram para a integração. Isto caracteriza um incipiente envolvimento dos estudantes nessas ações sociais, que visam à melhoria da qualidade de vida e o desenvolvimento local da comunidade mossoroense, o que é justificado pelo fato do curso ser oferecido no turno noturno e pela maioria dos alunos trabalharem diurnamente, o que os impede de se dirigir ao local onde são desenvolvidas as ações.

Há de se ressaltar, que essas atividades de extensão são realizadas esporadicamente, podendo envolver mais de uma disciplina e que, especificamente, no curso de Edificações que estamos analisando, não caracteriza uma prática pedagógica que contribuiu para a integração curricular.

Em relação às aulas de campo, envolvendo disciplinas do ensino médio e da formação profissional, $56 \%$ dos estudantes disseram que contribuíram para a integração, não havendo, portanto, unanimidade entre eles.

$\mathrm{Na}$ entrevista os estudantes revelaram que essa atividade acontece esporadicamente e envolve mais disciplinas de formação profissional, ainda que, eventualmente, possa contar com a participação de professores do ensino médio ou até mesmo ser promovida por esses. Um estudante afirmou: "as aulas de campo das quais participam mais de um professor, mas somente professores das disciplinas técnicas. Nessas aulas a gente tem mais clareza do que é a área de construção civil: terreno, solo, fábricas de materiais de construção etc." E um outro observou: "tivemos mais aulas de campo das disciplinas técnicas. Mas houve uma aula de campo de Geografia 
para que se observassem as rochas. Mas, as disciplinas do ensino médio não tiveram nenhuma aula fora disso."

De fato, as aulas de campo podem ensejar um trabalho interdisciplinar, pois a partir delas os estudantes podem apreender o imbricamento das categorias trabalho, ciência, tecnologia e cultura fundantes do currículo integrado, bem como o avanço dos sistemas produtivos e o reflexo deles na sociedade, já que elas proporcionam a aplicação prática do conhecimento teórico visto em sala de aula, o olhar crítico da realidade e a inserção futura no mundo do trabalho.

Contudo, essa atividade didática no campus Mossoró é, geralmente, programada por um único professor, o qual define o local de realização e os objetivos da aula, a fim de explorar o conteúdo da sua disciplina. Os demais professores que venham a participar dessas atividades também definem seus próprios objetivos, ou seja, não há qualquer diálogo prévio entre os docentes para a execução conjunta da tarefa, não ocorrendo, portanto, um trabalho interdisciplinar.

Ressaltamos que o desenvolvimento de atividades que envolvem várias disciplinas no ensino, na pesquisa e na extensão, por si só, não garante um trabalho coletivo, tampouco a integração curricular, ainda que sinalize nessa direção.

Enfim, em relação à prática profissional na forma de estágio supervisionado, todos os estudantes a realizam, pois é condição para a obtenção do diploma de técnico. No entanto, apenas $56 \%$ dos estudantes apontaram que essa atividade contribuiu para a integração do currículo.

Convém destacar que é por meio dessa atividade que o estudante, acompanhado por um professor-orientador, entra em contato direto com a atividade econômica na qual atuará e tem a oportunidade de articular a teoria da sala de aula com a prática exigida pela profissão. Assim, a prática profissional caracteriza-se como um momento de análise e apreensão do real, sendo, por excelência, uma atividade potencial de materialização do currículo integrado, ainda que ela seja pontual, inclusive por permitir a problematização dos eixos fundantes (trabalho, ciência, tecnologia e cultura) do ensino médio integrado.

Pelo exposto, podemos ilacionar que as atividades didáticas promovidas por alguns professores não demonstram que há, de fato, a materialização do currículo integrado no PROEJA no campus Mossoró do IFRN e, sim, que em determinados práticas, muito específicas, ocorre o envolvimento de professores de diversas disciplinas, não necessariamente de todos, tampouco em um trabalho conjunto.

Como assevera Machado (2006, p. 52), o objetivo dos currículos integrados "[...] é a concepção e a experimentação de propostas de ação didática que tenham, como eixo, a abordagem relacional de conteúdos tipificados estruturalmente como diferentes, [...] ainda que haja especificidades que devem ser reconhecidas."

Ou seja, a realização dessas atividades, de forma assistemática, por iniciativa de alguns professores e sem a participação de todos os estudantes, contribui muito pouco até mesmo para a dimensão metodológica da interdisciplinaridade e, consequentemente, dificulta a institucionalização do currículo integrado no curso de Edificações. 


\section{CONSIDERAÇÕES FINAIS}

Historicamente, a educação de nível médio no Brasil é marcada pela dualidade entre educação geral e formação profissional. A luta de educadores progressistas é pela implementação de uma formação para todos que transcenda essa dualidade e que esteja comprometida como as transformações sócio-econômico-político-cultural da sociedade, com a ampliação do acesso aos bens materiais produzidos e que permita aos estudantes adquirirem condições dignas para a inserção no mundo do trabalho, para o exercício consciente da cidadania e para prosseguirem estudos.

No caso específico da EJA, a articulação entre o ensino médio e a educação profissional é recente no país - 2005 - e sua materialização requer um currículo integrado, fundamentado na indissociabilidade do trabalho, ciência, tecnologia e cultura, além de materiais pedagógicos adequados para esse público.

No campus Mossoró do IFRN essa experiência começou a ser posta em prática em 2006, com a oferta do curso técnico integrado de Edificações na modalidade EJA. Conceitualmente, a perspectiva do curso - formação integral dos jovens e adultos - está bem definida, mas a própria organização curricular, que dispõe primeiro as disciplinas de ensino médio e depois as de formação profissional, inviabiliza o desenvolvimento do currículo integrado.

Ademais, as práticas pedagógicas elencadas neste trabalho demonstram que, de fato, não há a materialização concreta do currículo integrado no curso e, sim, que apenas em algumas ações didáticas, muito específicas, não sistematizadas e não planejadas coletivamente, ocorre o envolvimento de alguns professores de disciplinas distintas.

De qualquer forma, no conjunto das práticas relatadas, ainda que estas sejam promovidas por um número reduzido de professores, conforme evidenciaram os estudantes, constata-se o potencial que elas têm de contribuir para a realização do trabalho coletivo e o estabelecimento de diálogos entre as disciplinas, aspecto relevante, mas não o único, na construção do currículo integrado.

Nesse sentido, é imprescindível a reorganização do currículo e dos tempos e espaços de atuação dos professores, a fim de que possam incorporar à sua prática pedagógica, além do domínio técnico da ciência que professam, leituras que contribuam para a apropriação dos princípios fundantes do currículo integrado e para o conhecimento tecnológico para situar sua disciplina em um contexto abrangente no curso em que atua.

Com efeito, as práticas pedagógicas poderão incorporar as dimensões metodológica e ético-política do currículo integrado, de sorte a permitir aos estudantes não só se apropriarem dos conhecimentos técnicos inerentes ao curso, como também compreender a sociedade em que vivem e dela participar de forma autônoma, crítica e solidária.

\section{REFERÊNCIAS}

1. BRASIL. Decreto n. 5.478, de 24 de junho de 2005. Brasília, DF, 2005.

2. Decreto n. 5.840, de 13 de julho de 2006. Brasília, DF, 2006.

3. . Ministério da Educação. Programa Nacional de Integração da Educação Profissional 
com a Educação Básica na Modalidade de Educação de Jovens e Adultos. Formação Inicial e Continuada/Ensino Fundamental. Documento Base. Brasília, DF, 2007.

4. CENTRO FEDERAL DE EDUCAÇÃO TECNOLÓGICA DO RIO GRANDE DO NORTE. Plano de curso do curso técnico de nível médio integrado em Edificações na modalidade educação de jovens e adultos. Natal, RN, 2006.

5. FREIRE, Paulo. Pedagogia da autonomia: saberes necessários à prática educativa. 25 ed. São Paulo: Paz e Terra, 1996.

6. FRIGOTTO, Gaudêncio. A interdisciplinaridade como necessidade e como problema nas ciências sociais. Revista do Centro de Educação e Letras, UNIOESTE, Foz do Iguaçu, v. 10, n. 1, p. 41-62, 1. sem. 2008.

7. KRÜGER, Tânia R. Serviço social e saúde: espaços de atuação a partir do SUS. Revista Serviço Social \& Saúde. UNICAMP, Campinas, v. IX, n. 10, p. 123-45, dez. 2010.

8. MACHADO, Lucília R. S. PROEJA: o significado socioeconômico e o desafio da construção de um currículo inovador. In: TVescola: Programa Salto para o Futuro. EJA: formação técnica integrada ao ensino médio. Boletim 16, Rio de Janeiro, set. 2006.

9. __ Ensino médio e técnico com currículos integrados: propostas de ação didática para uma relação não fantasiosa. In: MOLL, Jaqueline e Colaboradores. (Org.). Educação profissional e tecnológica no Brasil contemporâneo: Desafios, tensões e possibilidades. Porto Alegre, RS: Artmed, 2010, p. 80-95.

10. RAMOS, Marise. Possibilidades e desafios na organização do currículo integrado. In FRIGOTTO, G.; CIAVATTA, M.; RAMOS, M. (Org.). Ensino Médio Integrado: concepção e contradições. São Paulo: Cortez, 2005, p. 106-127.

11. SILVA, Edna Lúcia da; MENEZES Estera Muszkat. Metodologia da Pesquisa e Elaboração de Dissertação. 3. ed. Florianópolis: Laboratório de Ensino a Distância da UFSC, 2001. 